\title{
2 YEAR FOLLOW-UP OF TANDEM OCCLUSION ACUTE ISCHEMIC STROKES TREATED BY MECHANICAL THROMBECTOMY WITHOUT EXTRA-CRANIAL STENTING
}

\section{BACKGROUND AND AIMS}

Mechanical thrombectomy (MT) is indicated for acute ischemic stroke caused by intracranial occlusion, associated with extra cranial occlusion or sub-occlusion (tandem occlusion). Therefore, very few tandem occlusions were included in the first MT trials and the best type of procedure for these occlusions is unknown, although highly debated.

\section{METHOD}

All patients who presented with an acute ischemic stroke and benefited from a MT at CHRU Besançon between January 1st 2015 and December 31st 2016 were included. They were monitored by the Besançon Stroke Registry who collected modified Rankin Scale scores at three months. Recurrence and endarteriectomy procedures were collected between 15th of January and 20th of January 2018 by phone call (and medical file when we had no answer). Symptomatic intracerebral hemorrhage was defined by a deterioration of the neurological exam (4 points on the NIHSS or more) and parenchymal hematoma 24 hours after the procedure.

\section{RESULTS}

During the period of inclusion, 27 patients had tandem occlusion. Concerning internal carotid artery (ICA) occlusion, the same procedure was performed for every patient: passing through ICA occlusion by guide only or with the help of an angioplasty balloon, then intra-cranial recanalization by aspiration or stent retriever. No ICA stenting was performed. Median NIHSS at admission was 18; $26 \%$ had a $0-2$ mRS at three months. Three patients had performed endarterectomy, in a mean time of 286 days after stroke. In January 2018, no patient had stroke recurrence, median follow-up was 23 months. One patient had retinal artery occlusion 38 days after the stroke with a $90 \%$ occlusion of ICA 24 hours postthrombectomy.

\section{Table 1}

$N$

Age, med 27

Female, \% 66

NIHSS, med 29,6

ETIOLOGY

Cardioembolism, \%

Large artery atherosclerosis (certain), \% 37,0

Large artery athrosclerosis (probable), \% 14,8

Other determined etiology, \%

Other undetermined etiology, \% 14,8

Dissection, \%

\section{THROMBUS LOCALISATION}

Right side, \%

ICA T, \%

$\mathrm{M} 1, \%$

$\mathrm{M} 2, \%$

Posterior circulation, \%

\section{OUTCOME}

$\mathrm{TICl} 0, \%$

$\mathrm{TICl} 2 \mathrm{~B}-3, \%$

mRS $0-2, \%$

25,9

Symptomatic intracerebral hemorrhage, \%

Death, \%

\section{DISCUSSION}

For tandem occlusion patients who are recanalized without acute ICA treatment, it seems crucial to seek the re-opening of the ICA and residual stenosis to prevent recurrence.

\section{CONCLUSION}

Recanalization of intracranial occlusion without ICA stenting at the hyperacute phase seems to be safe at two years. Acute stroke presenting with tandem ICA occlusion must be monitored on the long-term, since very few evidencebased recommendations exist in hyperacute management. 